\title{
The research of electrogeochemical technology in prospecting exploration and soil remediation
}

\author{
MEILAN WEN ${ }^{1}$, WEN GAO ${ }^{2}$, XIANRONG LUO ${ }^{3}$ \\ ${ }^{1}$ Guilin University of Technology, Guilin,541004,China, \\ meilanwen112@126.com \\ ${ }^{2}$ Guilin University of Technology,Guilin,541004,China, \\ 373949581@qq.com \\ ${ }^{3}$ Guilin University of Technology,Guilin,541004,China, \\ 1xr811@glute.edu.cn
}

The principle of electrogeochemical methods of exploration is based on extraction of charged particles of pathfinder elements in soil on surface, with 9V DC power, into the specially designed element-collectors. These collectors are embedded in the soil and connected to 9V DC as anodes and cathodes. Anomalies are found by analysing the concentration of metallogenic elements in the collectors. According to the principle, this technology can be used in prospecting and remediation and treatment of soil heavy metals. Being combined the geological conditions, the hidden ores are found on the basis of the anomalies of pathfinder elements from the deep ore bodies. And in the soil, the content of heavy metal elements containing charged particles can be reduced with being adsorbed to the collector under the applying power to the poles. In this study, electrogeochemical prospecting technology was used to search for hidden $\mathrm{Cu}-\mathrm{Mo}$ deposits in Fujian, China, and obvious metallogenic anomalies were found above the known ore bodies. At the same time, the experiment was carried out in the laboratory that this technology was used to extract the particles containing $\mathrm{Cr}$ and $\mathrm{Ni}$ from paddy fields in the north of Guangxi in China. The results show that the contents of $\mathrm{Cr}$ and $\mathrm{Ni}$ in the soil were decreased significantly after 21 days.

Therefore, it is believed that prospecting technology can not only be used to search for hidden minerals, but also play a certain role in the remediation of heavy metal contaminated soil. 